Studi Akuntansi \& Keuangan Indonesia

\title{
Dampak Pencatatan dan Jatuh Tempo Waran terhadap Harga Saham yang Disertai Waran di Indonesia
}

\author{
Stefan Suryawinata, Aldwin Tekadtuera, Dahlia Ervina * \\ Sekolah Bisnis dan Ekonomi - Universitas Prasetiya Mulya \\ BSD City Kavling Edutown I. 1, Jl. BSD Raya Utama, BSD City, Tangerang 15339
}

\section{Keyword:}

Abnormal Return, Derivative, Event Study, Efficient Market Hypothesis, Warrants

\section{Kata kunci:}

Abnormal Return, Derivatif, Event Study, Efficient Market

Hypothesis, Waran

*Corresponding Author: dahlia.ervina@pmbs.ac.id

\begin{abstract}
This research discusses the stock abnormal return effect of warrants to its underlying stock on its listing and maturity date. This study sample is the stock price changes of stocks backed with a warrant in the Indonesian stock market for the year 2008 to 2018using an event study approach to observe stock abnormal return effect on the listing and maturity date of warrants. The results of this research are that we find a significant negative abnormal return around the warrants' listing date. On the warrants' expiration date, we find a significant negative effect before and after the money warrants' maturity date. However, a different result is obtained for the observation of out-of-the-money warrants that do not show any significant abnormal return on the event window.
\end{abstract}

Abstrak. Penelitian ini membahas mengenai dampak pencatatan dan jatuh tempo waran terhadap abnormal return saham yang disertai waran di pasar Indonesia. Sampel dari penelitian ini diambil dari pergerakan harga saham yang disertai dengan waran di Indonesia pada periode 2008 sampai dengan 2018. Penelitian ini menggunakan metode event study untuk mengamati abnormal return saham saat peristiwa pencatatan dan jatuh tempo waran. Hasil penelitian yang kami dapatkan adalah kami menemukan adanya dampak signifikan abnormal return negatif saham pada kisaran tanggal pencatatan waran. Untuk pengamatan pada jatuh tempo waran, in the money, kami menemukan hasil abnormal return saham negatif signifikan sebelum dan sesudah tanggal jatuh tempo. Namun, hasil yang berbeda didapatkan oleh penelitian waran yang out of the money, tidak terlihat hasil abnormal return saham signifikan dalam jendela peristiwa. 


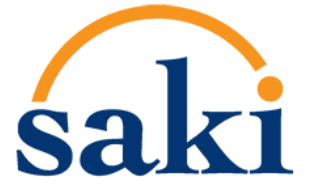

Studi Akuntansi \& Keuangan Indonesia

\section{Pendahuluan}

Instrumen derivatif adalah salah satu jenis aset keuangan yang mewakili klaim atas aset keuangan lain. Jenis-Jenis instrumen derivatif dapat berupa options, futures dan forward. Di Indonesia, waran tidak jarang disertakan per lembar saham yang dibeli oleh investor saat rights issue. Definisi dari waran menurut pasal 1 angka 5 Undang-Undang (UU) nomor 8 tahun 1995 tentang pasar modal yakni:

"Efek yang diterbitkan oleh suatu perusahaan yang memberi hak kepada pemegang efek untuk memesan saham dari perusahaan tersebut pada harga tertentu setelah 6 (Enam) bulan atau lebih sejak efek dimaksud diterbitkan"

Perbedaan antara waran saham dan opsi saham adalah, dengan waran perusahaan yang menentukan harga terbitnya waran dari sebuah saham yang didasarinya, sedangkan opsi saham merupakan sebuah kontrak untuk membeli atau menjual saham yang didasari dari pemain bursa lainnya. Kondisi waran di Indonesia saat ini sudah tercatat sebanyak 64 kali penawaran umum disertai waran yang diterbitkan oleh perusahaan terbuka selama 10 tahun terakhir dari 2008 hingga 2018, dan waran yang masih aktif pun hingga tahun 2019 jumlahnya sebesar 49 waran yang masih aktif diperdagangkan di Bursa Efek Indonesia. Semenjak tahun 2008, derivatif waran yang diterbitkan bersamaan dengan rights issue saat pengumuman HMETD (Hak Memesan Efek Terlebih Dahulu) tidak mengalami peningkatan atas penggunaan waran sebagai pemanis oleh para emiten. Jika dibandingkan dengan penelitian-penelitian terdahulu mengenai waran seperti pasar Australia, Amerika, Malaysia, Taiwan dan China (Aitken \& Segara, 2004; Florianová, 2015; Yip \& Lai, 2009; Clarke et al., 2011; Wong et al., 2018) perkembangan waran baru yang disertakan saat pengumuman di Indonesia tidaklah bertambah, namun berkurang dari jumlahnya pada tahun 2008 .

Payoff yang dihasilkan oleh opsi di saat expiration sebuah waran akan mempengaruhi keputusan investor terhadap opsi yang dipegangnya (Ross et al., 2016). Investor lebih memilih agar opsi yang dipegang hangus di saat harga exercise lebih tinggi dari harga jual saham induk di pasar saat itu juga. Kondisi ini dapat disebut sebagai "Out of the Money". Sedangkan, jika harga exercise lebih rendah dari harga jual saham induk di pasar saat itu, investor cenderung akan memilih untuk mencairkan opsi yang dipegang menjadi lembaran saham induk untuk meraup keuntungan, mengingat 


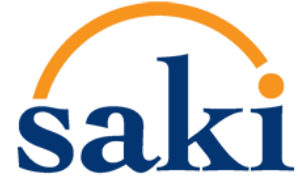

Studi Akuntansi \& Keuangan Indonesia

bahwa waran memberikan hak kepada pemegang efek untuk memesan saham dari pihak perusahaan. Hal ini menyebabkan lembaran saham yang beredar di pasar akan bertambah disaat investor mencairkan waran yang dipegangnya. Berdasarkan penjelasan Brealey et al. (2015), jumlah bertambahnya lembaran saham baru yang beredar pada pasar akan mengakibatkan sebuah tekanan pada harga sehingga harga saham akan sementara waktu berada dibawah nilai yang sebenarnya. Peristiwa ini dapat juga dikenal sebagai dilution effect. Harga saham tercerminkan oleh fundamental perusahaan, maka harga saham yang jatuh dikarenakan tekanan dari lembaran baru yang beredar akan menghasilkan imbal hasil yang besar daripada saham yang sebanding.

Proses untuk meminimalisir terpaparnya portofolio investor dari risiko atas fluktuasi dari pergerakan harga disebut sebagai hedging. Menurut Ross et al. (2016) investor akan melakukan lindung nilai (hedging) atas risiko investasi melalui instrumen derivatif. Dengan menggunakan waran, para investor dapat mengembangkan strategi lindung nilai pada harga saham yang dipegangnya. Hal ini menyebabkan adanya pola abnormal return dari aktivitas jual beli saham dapat terlihat selama periode berlangsungnya perdagangan waran tersebut. Yang akan dijadikan sudut pandang utama pada fenomena ini adalah perilaku investor pada saat waran mulai diperdagangkan dan hari-hari mendekati jatuh tempo waran.

Bursa Efek Indonesia saat ini sedang menyiapkan konsep waran terstruktur dimana institusi yang akan menerbitkan waran bukanlah dari pihak emiten, namun dari institusi keuangan atau dari perusahan efek besar sebagai sponsor untuk menerbitkan waran yang masih sehubungan dengan emiten yang disponsori. Bursa Efek Indonesia mengambil langkah ini dengan tujuan untuk menambah likuiditas dan menambah pilihan instrumen untuk berinvestasi pada bursa efek dalam negeri. Sebagai intrumen yang baru dikenal pada bursa Indonesia, maka peraturan yang bersangkutan dengan waran masih terbatas. Namun, waran masih dianggap akan menjadi hal populer bagi para investor untuk digunakan sebagai sarana investasi karena sifat waran yang menjadi acuan dari saham induk.

Penelitian terkait abnormal return karena peristiwa pencatatan waran menunjukkan hasil yang bervariasi. Chung et al. (2014), Xiao et al. (2013), Chung \& Hseu (2006) dan Chen \& Wu 


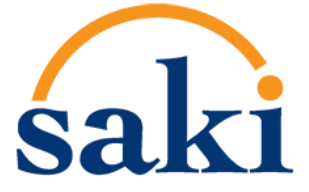

Studi Akuntansi dan Keuangan Indonesia, Vol. 3, No. 1, 2020 | E-ISSN: 2654-6221

Studi Akuntansi \& Keuangan Indonesia

(2001) menemukan abnormal return saham positif pada saat peristiwa pencatatan waran. Namun, Wong et al. (2018), Clarke et al. (2011) dan Aitken \& Segara (2004) menyimpulkan abnormal return saham negatif diakibatkan oleh peristiwa pencatatan waran. Untuk jatuh tempo pun hasil dari penelitian sebelumnya juga bervariasi bahwa saat waran jatuh tempo in the money, Wong et al. (2018), Chen \& Liao (2010), Chiang (2014), Chung et al. (2014), Xiao et al. (2013) dan Klemkosky (1978) mendapat hasil abnormal return negatif signifikan pada saat jatuh tempo. Untuk out of the money, Tang \& Wang (2011), Clarke et al. (2011) dan Chen \& Liao (2010) menyimpulkan bahwa waran yang berakhir out of the money tidak akan menghasilkan abnormal return pada harga saham. Di lain sisi, Wong et al. (2018), Chung et al. (2014), Chiang (2014), Chung \& Hseu (2006), Chen \& Wu (2001) menemukan abnormal return negatif saat jatuh tempo out of the money. Yang terakhir, Yip \& Lai (2009) dan Chan \& Wei (2001) yang menyimpulkan bahwa peristiwa pencatatan dan jatuh tempo waran tidak akan menghasilkan sebuah abnormal return pada harga saham.

Melihat penelitian atas opsi jenis waran yang telah dilakukan di negara lain yang bervariasi, maka penting untuk memahami perilaku investor dalam menggunakan lindung nilai berjenis waran berdasarkan payoff saat jatuh tempo dan pola abnormal return yang diakibatkan oleh aktivitas jual beli saham, pada titik sebelum, disaat, dan sesudah waran diperdagangkan dan hari-hari menjelang jatuh tempo waran. Untuk mendalami apakah waran di Indonesia masih berfungsi sebagai pemanis dalam pencarian modal lebih oleh para emiten. Diperlukan penelitian yang menyeluruh untuk melihat dampak yang sesungguhnya diakibatkan oleh waran terhadap abnormal return saham di Indonesia.

Maka dari pembahasan permasalahan di atas, tujuan dari penelitian ini adalah, untuk mengobservasi pola reaksi pasar terhadap waran pada pencatatan waran dan menjelang jatuh tempo waran di Indonesia, menggunakan abnormal return sebagai pengukur efek reaksi, dan untuk mengobservasi reaksi pasar terhadap payoff yang ditawarkan oleh waran dan membandingkan reaksi pasar terhadap terhadap payoff yang berbeda saat jatuh tempo atas semua perusahaan yang terdaftar di Bursa Efek Indonesia yang menyertai waran pada saat rights issue selama periode 2008-2018. Hasil dari penelitian diharapkan untuk bermanfaat bagi investor untuk lebih mengenali risiko yang ada 


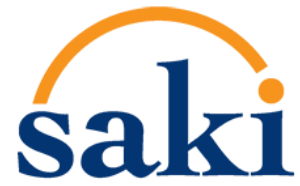

Studi Akuntansi \& Keuangan Indonesia

untuk pasar ekuitas yang didasari pasar derivatif dan pemerintah untuk dapat menjadikan hasil penelitian sebagai bahan masukan untuk menyusun regulasi mengenai salah satu pasar derivatif di Indonesia.

\section{Telaah Literatur Dan Pengembangan Hipotesis}

\section{Efficient Market Hypothesis}

Fama (1970) mengatakan bahwa konsep dasar teori Efficient Market Hypothesis (EMH) adalah kondisi dimana harga saham yang beredar di pasar secara utuh menggambarkan prospek perusahaan kedepannya, seperti profit perusahaan dan dividen perusahaan. Menurut teori, hal ini terjadi dikarenakan pasar sekuritas yang sangat kompetitif. Jika suatu saham dinilai undervalued, maka investor akan membelinya. Sementara itu, jika suatu saham dinilai overvalued, maka investor akan menjualnya. Oleh karena hal ini, harga saham perusahaan saat ini merupakan gambaran akurat nilai dari suatu perusahaan tersebut.

Implikasi dari teori ini adalah investor tidak dapat mengalahkan pasar secara konsisten. Namun, investor akan mendapatkan pendapatan konsisten dengan pendapatan pasar, yang sesuai dengan risiko yang diambil oleh investor tersebut. Teori ini mengatakan bahwa peluang investor untuk mengalahkan pasar dalam periode yang panjang sangat kecil.

Salah satu asumsi dari Efficient Market Hypothesis adalah kecepatan dari perusahaan untuk menyesuaikan kondisinya dengan berita yang masuk kedalam perusahaan. Hipotesis ini mengatakan bahwa harga saham akan disesuaikan dengan berita yang masuk dalam jangka waktu yang sangat pendek. Informasi akan masuk secara cepat kedalam komunitas investasi dan pasar akan dengan cepat menyesuaikan harga sekuritas dengan dampak informasi tersebut terhadap pendapatan dan dividen perusahaan. Saat informasi itu sampai kepada investor, harga saham sudah berubah, sesuai dengan informasi yang masuk. Hal ini menyebabkan investor tidak dapat mendapat profit dari informasi yang masuk.

Menurut Elton et al. (2009), abnormal return merupakan return yang dihasilkan dari sebuah portofolio atau perubahan harga, yang berbeda dari return yang diharapkan. Dalam teori, suatu pasar yang efisien tidak akan menghasilkan abnormal return, dikarenakan investor memiliki informasi yang 
Studi Akuntansi \& Keuangan Indonesia

sama dan bertindak sesuai dengan informasi yang diberikan. Namun, dalam prakteknya, abnormal return terjadi di pasar modal. Hal ini dikarenakan oleh beberapa hal, seperti strategi investasi dengan membeli saham dimana saham tersebut juga diinvestasikan oleh insider (orang dalam perusahaan), maupun membeli saham setelah terjadi hal diluar dugaan, yang menyebabkan reaksi berlebihan dari pasar.

\section{Pengembangan hipotesis}

Dalam penelitian sebelumnya, mengenai dampak waran terhadap abnormal return saham, terdapat banyak penelitian dengan latar belakang pasar yang berbeda-beda yang kesimpulannya masih diperdebatkan. Cheng \& Wu (2001) dan Chung \& Hseu (2006) mengatakan bahwa adanya dampak signifikan positif waran terhadap abnormal return saham perusahaan pada saat pencatatan waran. Hal ini terjadi dikarenakan adanya sentiment positif dari investor terhadap penerbit waran, yaitu perusahaan sehingga investor membeli saham perusahaan tersebut di hari pencatatan waran. Sentimen positif didapat dikarenakan investor melihat bahwa penerbit waran telah melakukan hedging dengan tujuan untuk menutupi kerugian jika waran berakhir in the money. Selain itu, baik Chung \& Hseu (2006) dan Cheng \& Wu (2001) menemukan bahwa aksi hedging yang dilakukan oleh penerbit waran dalam menurunkan risiko menghasilkan abnormal return saham yang positif juga bagi pergerakan harga saham yang terkait.

Dalam penelitian terdahulu lainnya didapatkan riset yang memiliki kesimpulan yang berbeda, yaitu waran memberikan dampak signifikan yang negatif terhadap pergerakan harga saham. Clarke $e t$ al. (2011) dan Aitken \& Segara (2004) menjelaskan pada penelitiannya di pasar Australia, bahwa tanggal pencatatan dari waran menghasilkan dampak harga yang negatif signifikan, sebelum dan sesudah pencatatan waran, terhadap pasar saham yang disertainya dikarenakan kurangnya dorongan tekanan pada harga saham dari pihak penerbit waran yang menandakan bahwa pihak penerbit tidak berupaya untuk melakukan lindung nilai yang menutupi exposure dari kerugian yang akan dihasilkan jika waran berakhir in the money. Dari absennya aktivitas lindung nilai dari pihak penerbit, investor memberikan pandangan yang negatif terhadap kurang keterlibatannya pihak penerbit waran. Clarke et 
Studi Akuntansi \& Keuangan Indonesia

al. (2011) juga menjelaskan bahwa adanya abnormal return saham yang diakibatkan dari pencatatan waran disebabkan oleh sebuah pihak dengan informasi dalam yang sangat kuat yang menjadi sorotan pada publik akan aktivitas yang dilakukannya menjadi sebuah sinyal pada pemain pasar lainnya.

Hasil yang serupa juga ditemukan oleh peneliti lain. Wong et al. (2018) menemukan bahwa di bursa China, waran berdampak signifikan negatif terhadap pergerakan harga saham. Wong et al. (2018) menjelaskan bahwa dampak harga yang negatif terjadi akibat speculation trading dari pasar waran berpindah juga kedalam pasar saham yang disertainya. Perilaku investor yang masih sedemikian spekulasi dalam melakukan perdagangan pada pasar waran lah yang membuat waran menjadi populer pada bursa China. Ia juga mengatakan bahwa ciri-ciri dari sebuah pasar saham yang memiliki korelasi dengan pergerakan pasar derivatif yang mendasarinya adalah salah satu faktor yang memperkuat hipotesa penelitiannya akan spekulasi dari pasar derivatif yang menular pada pasar saham.

Penemuan lainnya, menurut penemuan Wong et al. (2018), Chiang (2014), Xiao et al. (2013), Chung et al. (2014) dan Chen \& Liao (2010), abnormal return saham negatif yang signifikan ditemukan pada hari menjelang jatuh tempo waran untuk waran berjenis in the Money. Chiang (2014) menjelaskan bahwa pemegang opsi waran yang berjenis in the money ingin secepatnya mencairkan opsi tersebut menjelang tanggal jatuh tempo, yang dikarenakan adanya hedging yang dilakukan oleh penerbit waran sehingga investor memprediksi keuntungan yang didapat dari mencairkan waran akan mengecil pada saat jatuh tempo. Hal ini menyebabkan adanya selling pressure pada pasar yang lebih besar dibandingkan dengan average daily trading volume saham yang terkait, sehingga menyebabkan terciptanya abnormal return saham negatif yang signifikan. Hal tersebut juga menandakan tandatanda adanya efek dilusi untuk waran yang berakhir In the Money. Chung et al. (2014) menjelaskan bahwa signifikansi waran terhadap abnormal return saham dipengaruhi oleh posisi moneyness waran tersebut saat jatuh tempo. Chung et al. (2014) mendapatkan bahwa di Taiwan, waran yang jatuh in the money berdampak negatif signifikan terhadap abnormal return saham. Chung et al. (2014) mengatakan bahwa penyebab negatifnya dampak waran yang berakhir in the money disebabkan oleh 
Studi Akuntansi \& Keuangan Indonesia

adanya hedging yang dilakukan oleh penerbit waran dengan adanya pencairan waran yang dilakukan oleh investor.

Pada penelitian Chen \& Liao (2010) menjelaskan bahwa adanya tekanan untuk menjual pada pasar disaat waran jatuh tempo in the money dikarenakan pemegang waran mencairkan waran mereka untuk meraih keuntungan dari penjualan waran. Hal ini mengakibatkan tekanan untuk menjual pada harga selama periode exercise yang dalam penelitian ini adalah dari hari -4 hingga +1 . Sedangkan, untuk waran yang jatuh tempo out of the money, tekanan harga yang negatif dan signifikan hanya akan terlihat pada hari sebelum tanggal exercise saja sehingga setelah tanggal exercise tidak akan ada pergerakan harga yang signifikan untuk merubah harga pasar.

Tidak ditemukannya signifikansi waran terhadap abnormal return saham pada waran yang berakhir Out of the Money pada saat jatuh tempo. Hal ini ditemukan dari penelitian milik Tang \& Wang (2011), Clarke et al. (2011) dan Chen \& Liao (2010), dimana secara garis besar tidak signifikannya waran terhadap abnormal return saham pada waran yang berakhir out of the money dikarenakan investor lebih memilih untuk menghanguskan opsi mereka dibandingkan dengan mencairkan opsi yang dimiliki. Chen \& Liao (2010) menjelaskan bahwa perdagangan yang spekulatif pada pasar derivatif dan tanpa adanya mekanisme short-sales pada pasar derivatif dengan pasar saham dari pihak penerbit adalah alasan dari tidak signifikannya abnormal return saham yang dibuat saat waran berakhir Out of the Money.

Hasil yang berbeda ditemukan oleh peneliti Yip dan Lai (2009), yang meneliti mengenai dampak waran terhadap pergerakan harga saham di pasar saham di Malaysia, mengatakan bahwa hal ini terjadi dikarenakan investor dalam bursa saham Malaysia menganggap opsi saham lebih berpeluang untuk menghasilkan profit untuk investor dibanding dengan waran, walaupun waran memberikan alternatif lain bagi investor untuk berinvestasi. Selain itu, investor di Malaysia masih belum berpengalaman dalam perdagangan pada pasar waran, dimana karakteristik waran dengan opsi berbeda. Selain itu, Yip dan Lai (2009) mengemukakan bahwa pasar saham waran di Malaysia masih baru, sehingga tidak banyak investor yang melakukan perdagangan waran. 


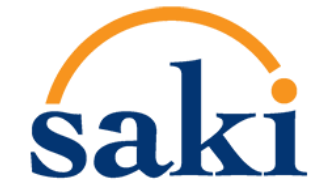

Studi Akuntansi \& Keuangan Indonesia

Pada pasar derivatif yang menyertai pasar ekuitas, terdapat faktor-faktor dari pasar derivatif yang mempengaruhi pergerakan pada pasar ekuitas. Peristiwa yang patut untuk diteliti berdasarkan pembahasan dari penelitian terdahulu adalah pada saat pencatatan (awal perdagangan) dan jatuh tempo waran. Dengan adanya pasar derivatif untuk melakukan lindung nilai terhadap investasi, aktivitas lindung nilai pada pasar akan bisa terlihat saat waran sudah dapat diperdagangkan dan mengalami pergerakan harga. Namun jika market tidak efisien dan terdapat sebuah pihak pada pasar yang dapat memprediksi pergerakan harga pada pasar untuk suatu peristiwa sebelum terjadinya peristiwa tersebut maka dapat dibilant pasar tersebut tidaklah efisien.

Berdasarkan hasil penelitian terdahulu mengenai pembahasan topik peristiwa saat pencatatan waran oleh Wong et al. (2018), Clarke et al. (2011), Chung \& Hseu (2006), Aitken \& Segara, (2004) dan Cheng \& Wu (2001) akan abnormal return saham yang dihasilkan saat peristiwa, maka didapatkan hipotesa pertama yakni:

$\mathbf{H}_{1}$ : Peristiwa pencatatan waran menghasilkan abnormal return saham pada periode yang diamati.

Sementara itu, berdasarkan Wong et al. (2018), Chung et al. (2014), Chiang (2014) dan Chen \& Liao (2010) yang mendapatkan hasil abnormal return yang signifikan dari peristiwa saat jatuh tempo waran in the money dan Tang \& Wang (2011) dan Clarke et al. (2011) yang tidak mendapatkan abnormal return signifikan saat jatuh tempo out of the money, maka didapatkan hipotesa kedua kami :

$\mathbf{H}_{2 \mathbf{a}}$ : Peristiwa jatuh tempo waran yang berakhir in the money menghasilkan abnormal return saham pada periode yang diamati.

$\mathbf{H}_{2 \mathrm{~b}}$ : Peristiwa jatuh tempo waran yang berakhir out of the money tidak menghasilkan abnormal return saham pada periode yang diamati.

\section{Metode penelitian}

\section{Populasi dan Sampel}




\section{saki}

Studi Akuntansi dan Keuangan Indonesia, Vol. 3, No. 1, 2020 | E-ISSN: 2654-6221

Studi Akuntansi \& Keuangan Indonesia

Populasi dari sampel yang digunakan peneliti untuk menguji hipotesa yakni seluruh tanggal pengumumman pembagian saham baru yang disertai waran oleh perusahaan-perusahaan yang terdaftar di Bursa Efek Indonesia (BEI). Dengan menggunakan metode purposive sampling, sampel yang diambil untuk penelitian adalah seluruh pengumuman penerbitan saham baru yang disertai waran untuk periode 2008 hingga 2018, dengan menggunakan waran yang sudah tidak lagi aktif diperdagangkan di BEI sejak tanggal 31 Desember 2018. Alasan peneliti memilih untuk melakukan penelitian pada periode tersebut dikarenakan asal mulanya jumlah waran yang diterbitkan bersamaan dengan rights issue yang paling banyak berada pada tahun 2008 dan terus meningkat popularitas akan pasar derivatifnya. Alasan lainya adalah dalam periode tersebut, terdapat periode bull (2008, 2013, 2015, 2018) dan bear $(2009,2010,2016,2017)$ dengan jangka waktu yang sama pada pasar yang mengurangi bias berdasarkan sentimen pasar.

Rincian hasil akhir pengumuman yang ditemukan oleh peneliti untuk digunakan sebagai sampel yakni, terdapat 64 peristiwa pengumuman rights issue yang disertai waran selama periode 2008-2018. Lima (5) peristiwa diumumkan pada tahun 2018, enam (6) peristiwa diumumkan pada tahun 2017, tujuh (7) peristiwa diumumkan pada tahun 2016, dua (2) peristiwa diumumkan pada tahun 2015, tiga (3) peristiwa diumumkan pada tahun 2014, empat (4) peristiwa diumumkan pada tahun 2013, enam (6) peristiwa diumumkan pada tahun 2012, delapan (8) peristiwa diumumkan pada tahun 2011, sembilan (9) peristiwa diumumkan pada tahun 2010, empat (4) peristiwa diumumkan pada tahun 2009, dan sebelas (11) peristiwa diumumkan pada tahun 2008.

Agar dapat melihat lebih dalam efek dari fenomena yang diteliti, peneliti menetapkan data harga pentupan saham akan meliputi 111 hari yang rinciannya 90 hari tersebut sebagai estimasi dan 21 hari merupakan periode pengamatan, yang akan digunakan untuk dibandingkan dengan hasil penelitian pada bursa Negara lainnya yang meneliti peristiwa sejenis. Tanggal terjadinya peristiwa, dalam hal ini berupa tanggal pencatatan waran dan tanggal jatuh tempo waran, akan secara berurutan dinotasikan dengan $t_{i}=0$ dan $t_{x}=0$. Periode pengamatan dari masing-masing peristiwa terdiri dari 10 hari sesudah dan sebelum hari peristiwa. Keputusan untuk meneliti 10 hari sesudah dan sebelum hari 
Studi Akuntansi \& Keuangan Indonesia

peristiwa ditentukan berdasarkan hasil penelitian yang telah dilakukan pada penelitian sebelumnya yang menemukan abnormal return signifikan pada kisaran -5 dan +5 dari tanggal peristiwa $(t=0)$ dan menambahkan 5 hari pada kisaran yang diobservasi. Periode estimasi akan digunakan untuk melihat kinerja saham sebelum periode pengamatan, sebelum hari peristiwa terjadi untuk mendapatkan jumlah abnormal return untuk sebuah saham.

Dari 64 data yang kami peroleh, 29 dari data yang telah terkumpul kami keluarkan dengan rincian, 18 dari data memiliki perdagangan waran yang masih aktif di pasar, 3 data dikeluarkan karena di tanggal peristiwa terdapat Corporate Action lainnya yang berjalan secara bersamaan dengan peristiwa yang sedang diteliti sehingga dikeluarkan untuk mendapatkan ketepatan yang lebih pasti bahwa abnormal return dihasilkan dari permasalahan yang sedang diteliti saja dan 8 dikeluarkan karena ketidaktersediaannya data atau saham tidak mengalami pergerakan harga selama masa periode peristiwa. Sisa dari sampel untuk penelitian ini terdapat 35 saham untuk diteliti keberadaan abnormal return saham pada saat pencatatan dan tanggal jatuh tempo waran. Dari 35 saham dalam rinci, 16 berakhir dengan status Out of The Money dan 19 In The Money.

\section{Analisis data}

Kami menggunakan metode event study berdasarkan penelitian terdahulu yang juga yang menggunakan metode event study (Wong et al., 2018; Florianova, 2015; Chiang, 2014; Chung et al., 2014; Xiao et al., 2013; Chen \& Liao, 2010; Yip \& Lai , 2009; Chung \& Hseu 2006; Aitken \& Segara, 2004; Chen \& Wu, 2001; Howe \& Howe, 2001; Hilliard \& Leitch, 1997; Rush \& Melicher, 1974). Oleh karena itu, penelitian akan dilakukan pada pengujian hipotesis untuk memecahkan argumen efficient market theory dan dilution effect pada bursa Indonesia. Penelitian ini juga menggunakan abnormal return sebagai pengukur tanda-tanda adanya pergerakan harga saham yang diakibatkan dari fenomena yang diteliti.

\section{Penyusunan Abnormal Return}


Studi Akuntansi \& Keuangan Indonesia

Hal pertama yang dilakukan oleh peneliti dalam pengolahan data adalah memasukkan data harga penutupan saham dan indeks harga gabungan saham harian yang diperoleh dari terminal Bloomberg. Harga saham harian yang dimasukkan meliputi event window ( $\mathrm{t}-10$ hingga $\mathrm{t}+10)$ dan estimation window (t-11 hingga t-101). Harga penutupan saham dan indeks harga gabungan saham harian yang telah dimasukkan, kemudian akan diolah dan dikumpulkan menjadi imbal hasil harian berdasarkan rumus capital gains yield (Jordan et al., 2015) sebagai berikut:

$$
R_{x(t)}=\frac{P_{x(t)}-P_{x(t-1)}}{P_{x(t-1)}}
$$

$R_{x(t)} \quad=$ Return saham $\mathrm{x}$ pada saat $\mathrm{t}$

$P_{x(t)} \quad=$ Closing Price saham x pada saat $\mathrm{t}$

$P_{x(t-1)}=$ Closing Price saham $\mathrm{x}$ pada saat $\mathrm{t}-1$

$\mathrm{t} \quad=-111,-110,-109, \ldots,-13,-12,-11$

Merekapitulasi sesuai langkah dari tahap sebelumnya, imbal hasil yang telah diolah akan diregresikan antara variabel imbal hasil harian saham sebagai variabel dependen dan imbal hasil harian dari indeks harga saham gabungan sebagai variabel independen untuk mendapatkan estimasi intercept $(\alpha)$ dan beta $(\beta)$ yang akan digunakan untuk menghitung tingkat abnormal return dari saham. Rumus regresi linear yang digunakan didapat berdasarkan Capital Asset Pricing Model (Jordan et al., 2015) yang dijabarkan sebagai berikut:

$$
\begin{gathered}
R_{x(t)}=\alpha_{x}+\beta_{x} \cdot R_{m(t)}+\varepsilon_{x(t)} \\
E\left(\varepsilon_{x(t)}=0\right)
\end{gathered}
$$

$R_{x(t)}=$ Return saham $\mathrm{x}$ pada saat $\mathrm{t}$

$\alpha_{x} \quad=$ Intercept saham $\mathrm{x}$; menunjukkan risk premium yang diharapkan sehubungan dengan firm specific factors

$\beta_{x}=$ Beta saham $\mathrm{x}$; menunjukkan tingkat volatilitas saham $\mathrm{x}$ terkait dengan pasar (systematic risk) 
Studi Akuntansi \& Keuangan Indonesia

$R_{m(t)}=$ Return pasar (IHSG) pada saat $\mathrm{t}$

$\varepsilon_{x(t)}=$ Unsystematic risk saham $\mathrm{x}$ sehubungan dengan firm specific factors pada saat $\mathrm{t}$

$\mathrm{t} \quad=-111,-110,-109, \ldots,-13,-12,-11$

Selanjutnya, intercept $(\alpha)$ dan beta $(\beta)$ akan diperhitungkan kedalam rumus yang telah kami susun untuk menghitung abnormal return bersamaan dengan return dari saham dan Indeks Harga Saham Gabungan (IHSG) untuk masing-masing periode dan saham sebagai berikut:

$$
A R_{x(t)}=R_{x(t)}-\alpha_{x}-\beta_{x} \cdot R_{m(t)}
$$

$A R_{x(t)}=$ Abnormal return saham $\mathrm{x}$ pada saat $\mathrm{t}$

$R_{x(t)} \quad=$ Return saham $\mathrm{x}$ pada saat $\mathrm{t}$

$\alpha_{x} \quad=$ Intercept saham $\mathrm{x}$; menunjukkan risk premium yang diharapkan sehubungan dengan firm specific factors

$\beta_{x} \quad=$ Beta saham $\mathrm{x}$; menunjukkan tingkat volatilitas saham $\mathrm{x}$ terkait dengan pasar (systematic risk)

$R_{m(t)}=$ Return pasar (IHSG) pada saat $\mathrm{t}$

Untuk dapat mempelajari pergerakan harian dalam periode event window, rata-rata abnormal return saham dari masing-masing periode peristiwa (t-10 hingga $\mathrm{t}+10)$ akan diperhitungkan dengan model berikut (Jordan et al., 2015):

$$
\overline{A R}_{(t)}=\frac{1}{n} \sum_{x=1}^{n} A R_{x(t)}
$$

$\overline{A R}_{(t)} \quad=$ Rata-rata abnormal return saham pada saat $\mathrm{t}$

$\mathrm{n}=$ = Jumlah peristiwa pencatatan / jatuh tempo waran

$A R_{x(t)}=$ Abnormal return saham $\mathrm{x}$ pada saat $\mathrm{t}$

$\mathrm{t} \quad=-10,-9,-8, \ldots, 0, \ldots, 8,9,10$ 
Studi Akuntansi \& Keuangan Indonesia

Setelah mendapatkan pola pergerakan harga saham, hasil yang didapat akan digunakan untuk mengobservasi dampak positif dan/atau negatif serta jarak dari abnormal return saham yang dihasilkan selama periode pengamatan. Akumulasi abnormal return dari harga saham yang dihasilkan oleh masing-masing perusahaan selama periode penelitian (t-10 hingga $t+10)$ akan diperhitungkan dan di rata-ratakan menjadi CAAR (Cumulative average abnormal return) menggunakan rumus berikut (Jordan et al., 2015):

$$
\operatorname{CARi}(\mathrm{tA}, \mathrm{tB})=\sum_{t 1}^{t 2} A R_{x(t)}
$$

$\mathrm{CARi}(\mathrm{tA}, \mathrm{tB}) \quad=$ Penjumlahan abnormal return saham perusahaan i untuk waktu peristiwa tA hingga tB.

$A R_{x(t)}=$ Abnormal return saham $\mathrm{x}$ pada saat $\mathrm{t}$

$\mathrm{T} \quad=-10,-9,-8, \ldots, 0, \ldots, 8,9,10$

Cumulative abnormal return saham akan diperhitungkan untuk mempertimbangkan adanya efek yang menggerakan harga saham secara permanen selama periode pengamatan dan arah dari pergerakan harga tersebut pada akhir periode pengamatan.

\section{Uji Signifikansi}

Setelah abnormal return dari saham untuk setiap hari peristiwa selama periode pengamatan telah diperhitungkan, peneliti kemudian menggunakan uji beda one-sample t-test untuk mendeteksi significance dari data untuk masing-masing periode peristiwa. Hasil dari uji beda akan digunakan untuk membuktikan hipotesa peneliti. Berhubung prasyarat akan harusnya distribusi normal akan data yang akan diuji menggunakan t-test, maka uji klasik normalitas shapiro-wilk akan digunakan sebelum melanjutkan pada uji one-sample t. Hasil yang didapat dari pengujian akan membuktikan kebenaran hipotesa yang disusun oleh peneliti berdasarkan penelitian terdahulu mengenai topik yang sedang dibahas.

Untuk data sampel berukuran kecil, in the money (20) dan out of the money (16). Peneliti menggunakan uji beda non-parametric approach untuk mendeteksi significance dari data untuk 
Studi Akuntansi \& Keuangan Indonesia

masing-masing periode peristiwa. Pendekatan ini dilakukan untuk sample size yang kami anggap kurang mencukupi, dibawah 20, agar menambah power dari hasil statistik yang diperoleh. Menurut Ott \& Longnecker (2015) non-parametric approach menghasilkan power yang jauh lebih kuat dibandingkan parametric approach (t-test) jika sample size yang diteliti berjumlah kecil dengan asumsi bahwa distribusi dari sampel tidaklah normal. Hasil yang didapat dari pengujian akan membuktikan kebenaran hipotesa yang disusun oleh peneliti berdasarkan penelitian terdahulu mengenai topik yang sedang dibahas.

\section{Hasil}

Uji signifikansi dilakukan oleh peneliti untuk menemukan ada atau tidaknya sebuah abnormal return yang diakibatkan oleh peristiwa yang diteliti. Dalam pengujian signifikansi, terdapat dua metode pengujian yakni parametric dan non-parametric yang akan digunakan berdasarkan asumsi normalitas data sampel.

\section{Uji T-test Saat Pencatatan}

Sehubungan dengan distribusi data yang normal, peneliti menggunakan metode pengujian parametric, single-sample t-test yang digunakan untuk memecahkan argumen dari teori permasalahan pada topik. Peneliti menggunakan metode pengujian parametric, single-sample t-test untuk memecahkan argumen dari teori efficient market pada pasar saham yang disertai waran di Indonesia. Berikut adalah tabel dari hasil uji penelitian dengan tingkat kepercayaan $95 \%$ atau $\boldsymbol{\alpha}=\mathbf{5} \%$ dengan $\mu=0$ sebagai null hypothesis yang diuji t, pada saat tanggal pencatatan waran.

Tabel 1 Hasil uji t-test di tanggal pencatatan waran

\begin{tabular}{cc|cccc}
\hline Tanggal & & t-value & t-crit & df & P-value \\
\hline-10 & 0.71502 & 2.042 & 35 & 0.4973 \\
\hline-9 & 0.19215 & 2.042 & 35 & 0.8487 \\
\hline $\mathbf{- 8}$ & $\mathbf{2 . 1 5 2 4}$ & $\mathbf{2 . 0 4 2}$ & $\mathbf{3 5}$ & $\mathbf{0 . 0 3 8 3 4}$ \\
\hline $\mathbf{- 7}$ & $\mathbf{- 2 . 5 2 8 8}$ & $\mathbf{2 . 0 4 2}$ & $\mathbf{3 5}$ & $\mathbf{0 . 0 1 6 1 1 ^ { * }}$ \\
\hline-6 & -0.34849 & 2.042 & 35 & 0.7296 \\
\hline $\mathbf{- 5}$ & $\mathbf{- 2 . 7 4 5 3}$ & $\mathbf{2 . 0 4 2}$ & $\mathbf{3 5}$ & $\mathbf{0 . 0 0 9 4 7 8 *}$ \\
\hline
\end{tabular}


Studi Akuntansi \& Keuangan Indonesia

\begin{tabular}{|c|c|c|c|}
\hline-4 & 0.56931 & 2.04235 & 0.5728 \\
\hline-3 & 0.30127 & 2.04235 & 0.765 \\
\hline-2 & -3.0619 & 2.04235 & $0.00421 *$ \\
\hline-1 & -0.68688 & 2.04235 & 0.4967 \\
\hline (Tanggal pencatatan) 0 & -1.4212 & 2.04235 & 0.1641 \\
\hline 1 & -0.16789 & 2.04235 & 0.8676 \\
\hline 2 & -1.2552 & 2.04235 & 0.2177 \\
\hline 3 & -1.4871 & 2.04235 & 0.146 \\
\hline 4 & -3.9649 & 2.04235 & $0.0003456 *$ \\
\hline 5 & 0.98046 & 2.04235 & 0.3336 \\
\hline 6 & 0.5851 & 2.04235 & 0.5622 \\
\hline 7 & -0.11646 & 2.04235 & 0.908 \\
\hline 8 & 1.4571 & 2.04235 & 0.154 \\
\hline 9 & 0.0087724 & 2.04235 & 0.9931 \\
\hline 10 & 0.1585 & 2.04235 & 0.875 \\
\hline
\end{tabular}

Dari tabel 1, dapat terlihat 5 hari yang menunjukan adanya abnormal return saham yang terbukti secara siginifikan, yakni pada hari t-8 (delapan hari sebelum tanggal pencatatan), t-7 (tujuh hari sebelum tanggal pencatatan), t-5 (lima hari sebelum tanggal pencatatan), t-2 (dua hari sebelum tanggal pencatatan) dan $\mathrm{t}+4$ (empat hari setelah tanggal pencatatan), dengan jumlah hasil $t$-test yang lebih tinggi dari $t$-crit. Maka demikian, hipotesa $\mathrm{H}_{1}$ yang disusun oleh peneliti diterima.

Berdasarkan tabel 2, dari hari-hari yang teruji menghasilkan tingkat abnormal return saham yang signifikan, t-8 (delapan hari sebelum tanggal pencatatan) menghasilkan abnormal return saham positif signifikan. Sedangkan t-7 (tujuh hari sebelum tanggal pencatatan), t-5 (lima hari sebelum tanggal pencatatan), $\mathrm{t}-2$ (due hari sebelum tanggal pencatatan) dan $\mathrm{t}+4$ (empat hari setelah tanggal pencatatan) menghasilkan abnormal return saham negatif signifikan.

Tabel 2 Rata-rata abnormal return signifikan saat pencatatan

\begin{tabular}{c|ccc}
\hline Tanggal & t-value & t-crit & Mean \\
\hline-8 & 2.1524 & 2.042 & 0.0163 \\
\hline-7 & -2.5288 & 2.042 & -0.0203 \\
\hline-5 & -2.7453 & 2.042 & -0.0214 \\
\hline-2 & -3.0619 & 2.042 & -0.0256 \\
\hline
\end{tabular}


Studi Akuntansi \& Keuangan Indonesia

$$
\begin{array}{l|lll}
4 & -3.9649 & 2.042 & -0.0732 \\
\hline
\end{array}
$$

(Sumber: data diolah 2019)

\section{Uji T-test Saat Jatuh Tempo Secara Keseluruhan}

Dari tabel 3, terlihat satu hari yang memiliki abnormal return saham yang terbukti signifikan secara statistik dari hasil hitung $\mathrm{t}$ ( $t$-value) yang lebih besar dari $t$-crit. Periode yang menghasilkan nilai uji-t yang lebih besar dari $t$-crit terdapat padi hari ke t-9 (sembilan hari sebelum tanggal jatuh tempo). Jika dilihat dari tabel 4, hari ke t-9 (sembilan hari sebelum tanggal jatuh tempo) menghasilkan rata-rata abnormal return saham yang negatif sebesar -0.01269 . Sisa dari hari penelitian tidak menunjukkan hasil uji yang terbukti signifikan secara statistik. Untuk mendalami hasil olah data lebih lanjut terhadap penemuan pada saat waran jatuh tempo, peneliti juga melakukan pengujian hipotesa pada masing-masing kondisi moneyness waran yang berbeda.

Berikut tabel dari hasil uji penelitian dengan kepercayaan 95\% atau $\alpha=5 \%$ dengan $\mu=0$ sebagai null hypothesis yang diuji t pada saat jatuh tempo secara keseluruhan:

Tabel 3 Hasil uji t-test saat jatuh tempo waran secara keseluruhan

\begin{tabular}{|c|c|c|c|}
\hline Tanggal & t-value & $\mathrm{t}$-crit df & $\mathrm{P}$-value \\
\hline-10 & 1.2134 & 2.04235 & 0.2331 \\
\hline-9 & -2.505 & 2.04235 & $0.01705 *$ \\
\hline-8 & -0.37351 & 2.04235 & 0.711 \\
\hline-7 & -0.45652 & 2.04235 & 0.6508 \\
\hline-6 & -0.65347 & 2.04235 & 0.5177 \\
\hline-5 & 1.3953 & $2.042 \quad 35$ & 0.1717 \\
\hline-4 & 1.2157 & 2.04235 & 0.2323 \\
\hline-3 & 0.36118 & 2.04235 & 0.7201 \\
\hline-2 & 1.3868 & 2.04235 & 0.1743 \\
\hline-1 & 0.50654 & 2.04235 & 0.6157 \\
\hline (Tanggal jatuh tempo) 0 & -1.3193 & 2.04235 & 0.1956 \\
\hline 1 & 0.98532 & 2.04235 & 0.3312 \\
\hline 2 & -1.4535 & 2.04235 & 0.155 \\
\hline 3 & -1.2598 & 2.04235 & 0.2161 \\
\hline 4 & 1.183 & $2.042 \quad 35$ & 0.2448 \\
\hline
\end{tabular}


Studi Akuntansi \& Keuangan Indonesia

\begin{tabular}{c|llll}
\hline 5 & 0.12417 & 2.042 & 35 & 0.9019 \\
\hline 6 & -0.97641 & 2.042 & 35 & 0.3356 \\
\hline 7 & 0.96385 & 2.042 & 35 & 0.3417 \\
\hline 8 & -1.7405 & 2.042 & 35 & 0.09055 \\
\hline 9 & 0.59456 & 2.042 & 35 & 0.556 \\
\hline 10 & 1.2685 & 2.042 & 35 & 0.213 \\
\hline \multicolumn{5}{c}{ (Sumber: data diolah 2019) } \\
\hline
\end{tabular}

Tabel 4 Rata-rata abnormal return signifikan saat jatuh tempo waran secara keseluruhan

\begin{tabular}{c|ll}
\hline Tanggal & t-value t-crit Mean \\
\hline-9 & -2.5052 .042 & -0.01269 \\
\hline \multicolumn{2}{c}{ (Sumber: data diolah 2019) }
\end{tabular}

Berdasarkan tabel 4, Periode dengan hasil uji abnormal return saham signifikan hanya terdapat pada hari t-9 (sembilan hari sebelum tanggal jatuh tempo) berada pada posisi negatif dengan jumlah -0.01269 .

\section{Uji Wilcoxon Saat Jatuh Tempo In The Money}

Berikut tabel dari hasil uji Wilcoxon dengan kepercayaan 95\% atau $\alpha=5 \%$ pada saat jatuh tempo in the money:

Tabel 5 Hasil uji wilcoxon saat jatuh tempo waran In the Money

\begin{tabular}{cc|ccc}
\hline Tanggal & & P-value & $\mathrm{V}$ & $\mathrm{df}$ \\
\hline-10 & 0.2162 & 71 & 19 \\
\hline $\mathbf{- 9}$ & $\mathbf{0 . 0 1 2 0 8} *$ & $\mathbf{3 9}$ & $\mathbf{1 9}$ \\
\hline-8 & 0.2943 & 76 & 19 \\
\hline-7 & 0.5706 & 121 & 19 \\
\hline-6 & 0.5459 & 122 & 19 \\
\hline-5 & 0.1231 & 147 & 19 \\
\hline-4 & 0.7285 & 95 & 19 \\
\hline-3 & 0.33 & 78 & 19 \\
\hline-2 & 0.2162 & 139 & 19 \\
\hline-1 & 0.7285 & 115 & 19 \\
\hline (Tanggal jatuh tempo) & 0 & 0.2774 & 75 & 19 \\
\hline 1 & 0.7562 & 96 & 19 \\
\hline 2 & 0.7012 & 94 & 19
\end{tabular}


Studi Akuntansi \& Keuangan Indonesia

\begin{tabular}{c|ccc}
\hline 3 & 0.8408 & 99 & 19 \\
\hline 4 & 0.5958 & 90 & 19 \\
\hline 5 & 0.3118 & 77 & 19 \\
\hline $\mathbf{6}$ & $\mathbf{0 . 0 2 6 6 4}$ & $\mathbf{4 6}$ & $\mathbf{1 9}$ \\
\hline 7 & 0.8695 & 110 & 19 \\
\hline 8 & 0.09731 & 60 & 19 \\
\hline 9 & 0.2024 & 140 & 19 \\
\hline 10 & 0.4524 & 126 & 19 \\
\hline \multicolumn{3}{|c|}{ Sumber: data diolah 2019) } &
\end{tabular}

Dari tabel 5, tedapat dua periode yang memiliki abnormal return saham yang terbukti signifikan secara statistik dari hasil p-value lebih kecil dari $\alpha=5 \%$. Yakni, pada hari ke t-9 (sembilan hari sebelum tanggal jatuh tempo) dengan rata-rata abnormal return saham -0.01327 dan t+6 (enam hari setelah tanggal jatuh tempo). Maka demikian, hipotesa $\mathrm{H}_{2 \mathrm{a}}$ yang diuji, akan adanya abnormal return saham pada periode pengamatan, diterima.

Berdasarkan tabel 6, Periode dengan hasil uji abnormal return saham signifikan terdapat pada hari t-9 (sembilan hari sebelum tanggal jatuh tempo) berada pada posisi negatif dengan jumlah 0.01327 dan $\mathrm{t}+6$ (enam hari setelah tanggal jatuh tempo) berada pada posisi negatif dengan jumlah0.00981 .

Tabel 6 Rata-rata abnormal return signifikan saat jatuh tempo waran in the money

\begin{tabular}{r|lll}
\hline Tanggal & P-value & V & Mean \\
\hline-9 & 0.01208 & 39 & -0.01327 \\
\hline 6 & 0.02664 & 46 & -0.00981 \\
\hline (Sumber: data diolah 2019)
\end{tabular}

\section{Uji Wilcoxon Saat Jatuh Tempo Out of The Money}

Berikut tabel dari hasil uji Wilcoxon dengan kepercayaan 95\% atau $\alpha=5 \%$ pada saat jatuh tempo in the money:

Tabel 7 Hasil uji wilcoxon saat jatuh tempo waran Out of the Money

\begin{tabular}{|c|c|}
\hline Tanggal & P-value V \\
\hline-10 & $\begin{array}{llll}0.1046 & 100 & 15\end{array}$ \\
\hline-9 & $\begin{array}{lll}0.2522 \quad 45 \quad 15\end{array}$ \\
\hline
\end{tabular}


Studi Akuntansi \& Keuangan Indonesia

\begin{tabular}{|c|c|c|c|}
\hline-8 & 0.4637 & 831 & 15 \\
\hline-7 & 0.2522 & 451 & 15 \\
\hline-6 & 0.0654 & 321 & 15 \\
\hline-5 & 0.3484 & $87 \quad 1$ & 15 \\
\hline-4 & 0.1754 & 411 & 15 \\
\hline-3 & 0.7057 & 601 & 15 \\
\hline-2 & 0.8209 & 731 & 15 \\
\hline-1 & 0.5966 & $57 \quad 1$ & 15 \\
\hline (Tanggal jatuh tempo) 0 & 0.3484 & 491 & 15 \\
\hline 1 & 0.9799 & 671 & 15 \\
\hline 2 & 0.1754 & 411 & 15 \\
\hline 3 & 0.2312 & 441 & 15 \\
\hline 4 & 0.2979 & 891 & 15 \\
\hline 5 & 0.6685 & 771 & 15 \\
\hline 6 & 0.5966 & 571 & 15 \\
\hline 7 & 0.9799 & 691 & 15 \\
\hline 8 & 0.5282 & 551 & 15 \\
\hline 9 & 0.3225 & $48 \quad 1$ & 15 \\
\hline 10 & 0.2312 & $44 \quad 1$ & 15 \\
\hline
\end{tabular}

(Sumber: data diolah 2019)

Dari tabel 7, tidak terdeteksi satu hari pun yang menunjukkan $p$-value lebih kecil dari $\alpha=$ 5\%. Hal ini menandakan bahwa tidak ada abnormal return saham yang terbukti signifikan secara statistik pada peristiwa waran yang berakhir out of the money. Berdasarkan hasil penelitian ini, hipotesa $\mathrm{H}_{2 \mathrm{~b}}$ yang menjelaskan bahwa tidak akan ada abnormal return saham yang signifikan pada saat waran jatuh tempo out of the money, diterima oleh peneliti.

\section{Diskusi}

Berdasarkan hasil penelitian di atas, hasil yang telah diuji pada pasar di Indonesia akan dibandingkan dengan penelitian terdahulu atas peristiwa-peristiwa pada pasar di negeri lain. Pembahasan akan dipisah menjadi dua yakni, saat pencatatan dan saat jatuh tempo waran.

\section{Abnormal Return Saham Saat Tanggal Pencatatan}

Hasil dari uji pada saat peristiwa pencatatan waran tidak konsisten dengan penemuan Chung et al. (2014), Xiao et al. (2013), Chung \& Hseu (2006) dan Chen \& Wu (2001) yang mendapatkan hasil abnormal return saham positif dan bersifat permanen sebelum dan sesudah pencatatan waran. Namun, 


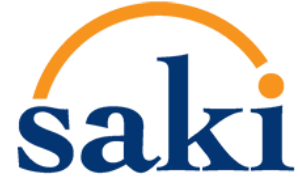

Studi Akuntansi \& Keuangan Indonesia

hasil peneilitan kami konsisten dengan penelitian Wong et al. (2018), Clake et al. (2011) dan Aitken \& Segara (2005) yang menjelaskan bahwa abnormal return saham negatif signifikan yang diakibatkan sebelum hari pencatatan waran diakibatkan oleh Reaksi pesimistis para investor yang menanggapi sikap pihak penerbit waran dengan memilih untuk "hold" saham yang disertainya dan tidak menempatkan tekanan untuk membeli pada pasar saham perusahaan. Aitken \& Segara (2005) juga menjelaskan di penelitiannya bahwa negative return yang tercipta pasca pencatatan waran diakibatkan oleh spekulasi pasar derivatif yang diberlakukan oleh informed traders.

\section{Abnormal Return Saham Tanggal Jatuh Tempo}

Hasil rata-rata abnormal return saham kumulatif yang negatif menjelang tanggal jatuh tempo waran in the money tidak konsisten dengan penemuan Chen \& Wu (2001), Chung et al. (2014) dan Chiang (2014), yang menemukan rata-rata akumulasi abnormal return positif sebelum hari jatuh tempo. Namun, hasil kami konsisten dengan penelitian pada pasar China yang diberlakukan oleh Chen dan Liao (2010). Berdasarkan penelitian Chen dan Liao (2010), hasil abnormal return yang terakumulasi 5 hari sebelum tanggal jatuh tempo tidak signifikan, namun menghasilkan akumulasi rata-rata Abnormal return negatif. Pada penelitiannya untuk di atas 5 hari sebelum tanggal jatuh tempo, ia juga menemukan abnormal return negatif signifikan pada waran call, atau disebut juga waran yang berakhir In the Money. Penelitian terdahulu oleh Klemkosky (1978) juga konsisten dengan hasil abnormal return negatif signifikan yang terjadi di jauh hari sebelum tanggal jatuh tempo. Ia menjelaskan bahwa investor sudah dapat memprediksi bahwa waran akan berakhir in the money meskipun masih tersisa waktu sebelum tanggal jatuh tempo dari waran, sehingga portfolio yang telah dipegang lama sebagai lindung nilai dilepas menjelang tanggal jatuh tempo dan menciptakan selling pressure pada pasar.

Penemuan oleh Chung et al. (2014) dan Chiang (2014) juga tidak konsisten dengan hasil penelitian kami pada hari peristiwa $(\mathrm{t}=0)$ dimana rata-rata abnormal return di hari tersebut adalah negatif dan signifikan. Chiang (2014) menjelaskan bahwa negatif return yang dihasilkan pada hari tersebut diakibatkan dari banyaknya investor yang berburu untuk mencairkan waran mereka menjadi 


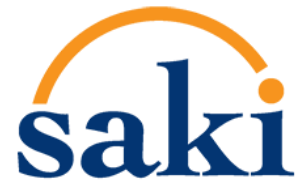

Studi Akuntansi \& Keuangan Indonesia

lembaran saham, sehingga dari hal tersebut terbuatlah tekanan "Sell" pada pasar. Hal tersebut juga dapat menandakan tanda-tanda keberadaan efek dilusi untuk waran yang berakhir In the Money. Di pasar Indonesia yang telah kami teliti, rata-rata abnormal return pada hari $\mathrm{t}=0$ menunjukan negatif namun tidak terbukti signifikan secara statistik.

Untuk hasil dari abnormal return yang diobservasi setelah hari peristiwa, penelitian terdahulu (Chung et al., 2014; Chiang, 2014; Chung et al, 2006) menjelaskan bahwa dampak negatif setelah hari peristiwa adalah hasil dari pencairan waran yang masih berlangsung yang mengakibatkan tekanan pada pasar untuk menjual. Dari hasil penelitian kami ditemukan satu hari yang memberikan tandatanda adanya abnormal return yang signifikan, 6 hari setelah hari peristiwa.

Kesamaan antara hasil dari sampel In the money dengan keseluruhan sampel pada saat jatuh tempo dapat diakibatkan oleh jumlah sampel waran in the money yang lebih banyak daripada out of the money. Dikarenakan sebagian besar dari waran yang di amati oleh peneliti selama periode 2008 hingga 2018 memiliki jumlah pembagian waran berakhir dengan in the money yang sedikit lebih banyak, sebesar $55 \%$.

Hasil uji kami pada saat waran jatuh tempo out of the money, konsisten dengan penemuan Clarke et al. (2011), Tang \& Wang (2011) dan Chen \& Liao (2010) yang juga sama menyimpulkan, waran dengan jatuh tempo Out of the Money tidak menghasilkan sebuah abnormal return yang signifikan pada pasar saham yang disertainya. Chen \& Liao (2010) menjelaskan bahwa perdagangan yang spekulatif pada pasar derivatif dan tanpa adanya mekanisme short-sales pada pasar derivatif dengan pasar saham dari pihak penerbit adalah alasan dari tidak signifikannya abnormal return yang dibuat saat waran berakhir Out of the Money.

Hasil penelitian pada waran yang berakhir Out of the Money tidak konsisten dengan penelitan sebelumnya (Wong et al., 2018; Chiang, 2014; Chung et al., 2014; Chung \& Hseu, 2006; Chen \& Wu, 2001) yang mendapatkan hasil Abnormal return signifikan pada penelitian masing-masing pasca tanggal jatuh tempo waran. 


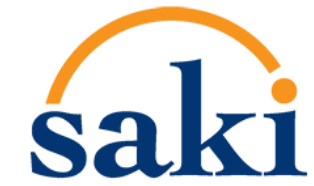

Studi Akuntansi \& Keuangan Indonesia

Secara keseluruhan, jumlah waran yang berakhir In the Money pada pasar Indonesia selama periode 2008 hingga 2018 lebih banyak jumlahnya daripada waran yang berakhir Out of the Money. Jumlah selisih antara waran yang In the Money (55\%) dan Out of the Money (45\%) hanya berbeda 10\%. Demikian dapat terlihat gambaran yang serupa saat menguji data waran secara keseluruhan dengan waran yang berakhir In the Money.

Dapat kami simpulkan saat waktu jatuh tempo secara keseluruhan, investor kurang tertarik untuk bermain pada pasar dengan waran, dibandingkan stock polos (tanpa disertai derivatif) yang jauh lebih likuid pergerakannya dibandingkan saham yang diberikan pemanis. Ditambah lagi mekanisme pasar di Indonesia yang menurut peraturan bursa efek Indonesia nomor II-A tentang perdagangan efek bersifat ekuitas, bahwa untuk memberikan kesempatan menukarkan waran menjadi saham, maka perdagangan waran berakhir 4 hari sebelum tanggal jatuh tempo. Penjelasan lainnya adalah Investor merasa bahwa biaya saat membeli waran dari pasar sekunder ditambah biaya administrasi untuk mencairkan waran menjadi saham sangatlah tidak menguntungkan, sehingga untuk waran yang in the money mereka lebih memilih untuk menghanguskan waran yang dipegangnya.

\section{Kesimpulan, Implikasi, dan keterbatasan}

Berdasarkan hasil akhir penelitian, bisa disimpulkan bahwa pada saat listing dan jatuh tempo suatu waran akan menghasilkan dampak abnormal return pada saham perusahaan terkait. Pada saat pencatatan waran, terdapat abnormal return saham negatif yang terjadi lebih besar dari abnormal return saham positif. Hal tersebut diakibatkan oleh pihak investor yang melakukan spekulasi pada pasar untuk meraup imbal hasil jangka pendek. Pada saat jatuh tempo, terdapat abnormal return saham kumulatif yang negatif menjelang tanggal jatuh tempo waran in the money. Sedangkan, waran dengan jatuh tempo out of the money tidak menghasilkan sebuah abnormal return yang signifikan pada saham yang disertainya.

Beberapa implikasi yang dapat diterapkan oleh pelaku pasar saham terkait dengan temuan dalam penelitian ini. Bagi pemerintah, agar pemerintah semakin mendukung pengembangan pasar 


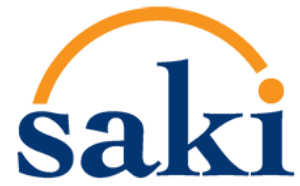

Studi Akuntansi \& Keuangan Indonesia

instrumen derivatif, terutama waran, di Indonesia. Dengan pasar instrumen derivatif yang lebih besar, diharapkan semakin banyak investor yang tertarik untuk berinvestasi sehingga mekanisme pasar dan pergerakan nilai instrumen derivatif dapat bergerak dengan ekspektasi pasar karena bukan hanya segelintir investor yang memiliki kendali. Dukungan ini dapat dilakukan dengan edukasi kepada pelaku pasar modal, maupun pemberian insentif kepada emiten yang hendak menerbitkan instrumen derivatif. Bagi investor, agar investor dapat melakukan investasi dan divestasi waran di pasar modal, sesuai dengan tujuan investasinya, yaitu dengan menggunakan timeline sesuai temuan penelitian dimana terdapat abnormal return positif dan negatif pada hari-hari tertentu terkait event pencatatan dan jatuh tempo waran.

Penelitian ini tidak luput dari keterbatasan, pertama periode observasi pada penelitian ini yang tidak jauh. Penelitian selanjutnya dapat memperlebar periode observasi untuk melihat apakah terdapat abnormal return pada hari yang lebih jauh lagi dari hari yang diobservasi pada penelitian ini. Penelitian selanjutnya dapat menggunakan titik lain untuk dilakukan observasi contohnya pada saat tanggal pengumuman agar dapat melihat lebih dalam titik mana yang paling berdampak terhadap abnormal return sahamnya. Kedua, setiap tahunnya pengumuman atas rights issue yang disertai waran yang tercatat pada website KSEI terdapat kurang dari 10 pengumuman. Semakin peneliti memperlebar periode yang diteliti maka kemungkinan penelitian akan mendapatkan hasil yang bias akan bertambah dikarenakan kondisi trend pada pasar yang berbeda-beda untuk setiap periode. Kondisi dari trend pasar akan mempengaruhi ciri-ciri investor pada pasar saham sehingga abnormal return yang diharapkan pada penelitian akan juga ikut terpengaruhi. Namun untuk mencukupi jumlah data agar memenuhi Central Limit Theorem sangatlah diperlukan, maka perpanjangan periode yang di observasi sangat diperlukan untuk menambah akurasi dari penelitian. Untuk peneliti selanjutnya, dapat menambahkan jumlah sampel yang digunakan. 
Studi Akuntansi \& Keuangan Indonesia

\section{Daftar Pustaka}

Aitken, M. \& Segara, R. (2004). Impact of warrant introductions on the behavior of underlying stocks: Australian evidence. Accounting and Finance, 45, 127-144. Retrieved from https://doi.org/10.1111/j.1467-629x.2004.00126.x.

Brealey, R. A., Myers, S. C., Marcus, A. J. (2015). Fundamentals of Corporate Finance (8th ed International ed). USA: McGraw-Hill Education, 448.

Chan, Y. C., Wei, K. C. J. (2001). Price and volume effects associated with derivative warrant issuance on the stock exchange of Hong Kong. Journal of banking and Finance, 25, 1401-1426. Retrieved from https://doi.org/10.1016/S0378-4266(00)00138-2.

Chen, K. C. \& Wu, L. (2001). Introduction and expiration effects of derivative equity warrants in Hong Kong. International review of financial analysis, 10, 37-52. Retrieved from https://doi.org/10.1016/S10575219(00)00044-2.

Chen, K. C. \& Liao, X. H. (2010). Expiration effects of covered warrants in China. The Chinese economy, 43. Retrieved from https://doi.org/10.2753/1097-1475430605.

Chiang, Chin-Han. (2014). Stock returns on option expiration dates: Prince impact of liquidity Trading. Journal of empirical Finance, 28, 273-290. Retrieved from https://doi:10.1016/j.jempfin.2014.03.003.

Chung, S. L., Liu, W. R., Tsai, W. C. (2014). The impact of derivatives hedging on the stock market: evidence from taiwan's covered warrants market. Journal of Banking \& Finance, 42, 123-133. Retrieved from https://doi.org/10.1016/j.jbankfin.2014.01.027.

Chung, H. \& Hseu, M. M. (2006). Why do the market impacts of derivative warrant differ from those of standard options? Evidence from emerging markets. Investment Management and financial innovations, 3(2)138-153.

Clarke, M., Gannon, G., Vinning, R. (2011). The impact of warrant introduction: the Australian experience. Review of Pacific basin financial markets and policies, 14, 213-269. Retrieved from DOI: 10.1142/S021909151100224X.

Elton, E. J., Gruber, M. J., Brown, S. J., Goetzmann, W. N. (2009). Modern portfolio theory and Investment analysis (8th ed). John wiley \& sons, 419-421.

Fama, E. F. (1970). Efficient capital markets: A review of theory and empirical work. The journal of Finance, 25(2), 383-417.

Florianová, Hana. (2015). Delta-hedging of warrants: Evidence from Frankfurt stock exchange. Procedia Economic and Finance, 30, 239-244. Retrieved from https://doi.org/10.1016/S2212-5671(15)01291-5.

Hilliard, J. E. \& Leitch, R. A. (1977). Analysis of the warrant hedge in a setable paretian market. The journal of financial and quantitative analysis, 12, 85-103. Retrieved from www.jstor.org/stable/2330289. 
Studi Akuntansi \& Keuangan Indonesia

Howe, J. C. Y. \& How, J. S. (2001). Warrants in initial public offerings: empirical evidence. Journal of Business, 74, 433-457. Retrieved from https://www.jstor.org/stable/10.1086/321933.

Jordan, B. D., Miller Jr, T. W., Dolvin, S. D. (2015). Fundamentals of Investments (7th ed). USA: Mcgrawhill Education, p. 4, 59, 150, 157, 228, 420-421, 559.

Klemkosky, R. C. (1978). The impact of option expiration on stock prices. The journal of financial and quantitative analysis, 13, no.3, 507-518. Retieved from https://www.jstor.org/stable/2330155.

Ott, L. R. \& Longnecker, M. (2015). An introduction to statistical methods and data analysis (7th ed). USA: Cengage Learning, p.269, 271, 330.

Otoritas Jasa Keuangan. (1995). Undang-Undang Nomor 8 Tahun 1995 Tentang Pasar Modal. Retrieved from https://www.ojk.go.id/id/kanal/pasar-modal/regulasi/undang-undang/Documents/Pages/undangundang-nomor-8-tahun-1995-tentang-pasarmodal/UU\%20Nomor\%208\%20Tahun\%201995\%20(official).pdf

Ross, S. A., Westerfield, R. W., Jordan, B. D., Lim, J., Tan, R. (2016). Fundamentals of Corporate Finance (Asia global 2nd edition). USA: Mcgrawhill, 2, p. 805, 832-835, 856-857.

Rush, D. F., \& Melicher, R. W. (1974). An empirical examination of factors which influence warrant prices. The journal of Finance, 29, 5, 1449-1466. Retrieved from https://www.jstor.org/stable/2978550.

Tang, K., Wang, C. (2011). Are Chinese warrants derivatives? Evidence from connections to their underlying stocks. Quantitative Finance, 13, 1225-1240. Retrieved from https://doi.org/10.1080/14697688.2012.740570.

Wong, W. K., Lean, H. H., McAleer, M. J., Tsai, F. T. (2018). Why are warrant markets sustained in taiwan but not in China? Sutainability, 10. Retrieved from doi:10.3390/su10103748.

Xiao, W. L., Zhang, W. G., Yao, Z., Wang, X. H. (2013). The impact of issuing warrant and debt on behavior of the firm's stock. Economic modelling, 31, 635-641. Retrieved from https://doi.org/10.1016/j.econmod.2013.01.007.

Yip, Y. Y. \& Lai, M. M. (2009). Impact of warrant lisings on its underlying stocks: the Malaysia evidence. Academy of accounting and financial studies journal, 13 . Retrieved from https://www.researchgate.net/publication/289195896_Impact_of_warrant_listings_on_its_underlying_s tocks_The_Malaysian_evidence/citations. 